Louisiana State University

LSU Digital Commons

$2-1-2010$

\title{
Laboratory evaluation of novaluron as a rodent feed-through insecticide against sand fly larvae (Diptera: Psychodidae)
}

\author{
T. M. Mascari \\ Louisiana State University \\ L. D. Foil \\ Louisiana State University
}

Follow this and additional works at: https://digitalcommons.Isu.edu/entomology_pubs

\section{Recommended Citation}

Mascari, T., \& Foil, L. (2010). Laboratory evaluation of novaluron as a rodent feed-through insecticide against sand fly larvae (Diptera: Psychodidae). Journal of Medical Entomology, 47 (2), 205-209.

https://doi.org/10.1603/ME09117

This Article is brought to you for free and open access by the Department of Entomology at LSU Digital Commons. It has been accepted for inclusion in Faculty Publications by an authorized administrator of LSU Digital Commons.

For more information, please contact ir@lsu.edu. 


\title{
Laboratory Evaluation of Novaluron as a Rodent Feed-Through Insecticide Against Sand Fly Larvae (Diptera: Psychodidae)
}

\author{
T. M. MASCARI ${ }^{1}$ AND L. D. FOIL \\ Department of Entomology, Louisiana State University Agricultural Center, Agricultural Experiment Station, \\ 402 Life Sciences, Baton Rouge, LA 70803
}

\section{J. Med. Entomol. 47(2): 205-209 (2010); DOI: 10.1603/ME09117}

\begin{abstract}
Experiments were conducted to evaluate novaluron as a feed-through larvicide to control immature phlebotomine sand flies (Phlebotomus papatasi Scopoli) (Diptera: Psychodidae). The minimum effective concentration of novaluron against sand fly larvae fed hamster feces treated with novaluron, or feces of hamsters fed a diet containing novaluron, was 9.88 and $9.88 \times 10^{-1} \mathrm{mg} / \mathrm{kg}$, respectively. Feces of novaluron-treated hamsters were held under conditions simulating the inside of a rodent burrow for up to $30 \mathrm{~d}$, and all larvae that consumed these feces died before pupation; a significant reduction in treated larval survival relative to control was observed when the feces were aged for up to $150 \mathrm{~d}$. Novaluron was shown to be effective as a feed-though larvicide when novalurontreated food made up only a portion of the diet of hamsters. The results of this study suggest that novaluron could be effective as a rodent feed-through insecticide in a field setting.
\end{abstract}

KEY WORDS Phlebotomus papatasi, novaluron, sand fly control

Phlebotomine sand flies (Phlebotomus papatasi Scopoli) (Diptera: Psychodidae) are major biting pests of man and are the vectors of the protozoan parasites that cause leishmaniasis. There are an estimated 2 million new cases of leishmaniasis annually, and 12 million people are currently believed to be infected (World Health Organization [WHO] 2008). In North Africa, the Middle East, and Southwest Asia, P. papatasi is the primary vector of Leishmania major Yakimoff and Schokor, the causative agent of zoonotic cutaneous leishmaniasis (ZCL).

Despite their importance, there are no effective control or preventive measures currently available for sand flies in ZCL foci. In arid and semiarid foci, $P$. papatasi exhibits a close association with several burrowing rodent that serve as reservoirs of L. major. In ZCL foci in the Old World, rodent burrows are considered to be the primary habitats for immature $P$. papatasi, and sand fly larvae have been observed feeding on the feces of rodents. Therefore, rodent feedthrough insecticides are a potential means of controlling sand fly larvae.

Proof of concept for rodent feed-through control of larvae of $P$. papatasi was established in laboratory studies using the benzoylurea chitin synthesis inhibitor novaluron (Mascari et al. 2007b). All diet concentrations of novaluron tested in a preliminary rodent feed-through study $(9.88,98.8$, and $988 \mathrm{mg} / \mathrm{mg}$ ) were $100 \%$ effective in killing sand fly larvae that fed on the feces of novaluron-treated rodents (Mascari et

\footnotetext{
${ }^{1}$ Corresponding author, e-mail: tmascari@agcenter.lsu.edu.
}

al. 2007b). However, additional laboratory studies are required to determine if novaluron is appropriate for field use. There were three objectives of this study, (1) to determine the minimum concentration of novaluron mixed with hamster feces that will prevent development of sand fly larvae and the minimum dose of novaluron for hamsters that will be effective as a feed-through against sand fly larvae, (2) to determine the persistence of the larvicidal effect of novaluron in hamster feces held under simulated field conditions, and (3) to determine the effectiveness of novaluron as a feed-through in preventing the development of sand fly larvae when novaluron-treated food makes up only a portion of a hamster's daily diet.

\section{Materials and Methods}

Sand Flies. The sand flies used in these studies were from a laboratory colony established at Louisiana State University of a Turkish strain of P. papatasi (Mascari et al. 2007b). The larvae were reared using a larval diet composed of a composted and dried 1:1 mixture of rabbit feces and rabbit chow (Young et al. 1981). Adult sand flies were provided $20 \%$ sucrose solution ad libitum, and obtained blood meals from Syrian hamsters. The colony was maintained in environmental chambers at $28^{\circ} \mathrm{C}, 90 \% \mathrm{RH}$.

Hamsters. Syrian hamsters were housed individually in micro-isolator cages. The maintenance of the hamsters and all experimental procedures followed Animal Care and Use Protocol No. 05-074, which was approved by the Institutional Animal Care and 
Use Committee at Louisiana State University, Baton Rouge, LA. Research involving the hamsters was conducted in compliance with the Animal Welfare Act and other federal statutes and regulations relating to animals and experiments involving animals and adheres to principles stated in the Guide for the Care and Use of Laboratory Animals, NRC Publication, 1996, edition.

Experiment 1: Direct Treatment of Hamster Feces. A series of 10-fold dilutions of technical novaluron (98.8\% a.i., Makhteshim Agan Industries Ltd., Tel Aviv, Israel) was prepared in acetone. The feces of untreated hamsters were collected and dried at room temperature for $7 \mathrm{~d}$. The feces were crushed using a sterilized glass mortar and pestle and treated with novaluron solutions (at a rate of $1 \mathrm{ml} / 1 \mathrm{~g}$ feces) yielding eight concentrations ranging from $9.88 \times 10^{-5}$ to $988 \mathrm{mg} / \mathrm{kg}$ novaluron. A solvent-control diet (made by treating feces with acetone) also was prepared. The acetone was allowed to evaporate for $12 \mathrm{~h}$, and the feces were stored at $-80^{\circ} \mathrm{C}$ until used. Larval bioassays were conducted as described by Mascari et al. (2007a). A portion of feces $(200 \mathrm{mg}$ ) was placed on the plaster surface of each bioassay vial. Ten-second instar (13 \pm $1 \mathrm{~d}$ old) larvae then were transferred to each bioassay vial and held in an environmental chamber at $28^{\circ} \mathrm{C}$, $90 \%$ RH. Four bioassay vials were prepared for each concentration of novaluron and for the control group; a priori power analysis $(\alpha=0.05,1-\beta=0.80)$ was conducted, and this sample size allowed us to detect differences of at least $7.01 \%$ mortality between the groups of larvae (Minitab Statistical Software 2005).

Larvae were observed under magnification daily, and larval mortality (defined as the lack of response to prodding with a blunt probe after $15 \mathrm{~s}$ ) and the percentage of sand flies that successfully emerged as adults were recorded. Larvae were observed for abnormal behavioral and morphological characteristics. Evidence of feeding (the presence of frass in the vials and dark material in the guts of larvae) also was monitored. The percent mortality of sand flies and the age of sand flies at death were compared with repeated-measures analysis of variance (ANOVA) performed with the general linear model (GLM) procedure (SAS Institute 2001). The Tukey multiple comparison procedure was used to separate significantly different means.

Experiment 2: Minimum Effective Dose as a FeedThrough. Hamster diets were prepared by adding technical novaluron to a meal-form laboratory rodent diet (5001 Rodent Diet, LabDiet, PMI Nutrition International, Brentwood, MO). Novaluron and the diet were thoroughly mixed to achieve six concentrations: $9.88 \times 10^{-5}, 9.88 \times 10^{-4}, 9.88 \times 10^{-3}, 9.88 \times 10^{-2}$, $9.88 \times 10^{-1}$, and $9.88 \mathrm{mg} / \mathrm{kg}(9.88 \mathrm{mg} / \mathrm{kg}$ has been shown previously to be effective as a feed-through against sand fly larvae and was used as the highest concentration of novaluron tested in this experiment; Mascari et al. 2007b). A control diet (untreated laboratory rodent diet) also was prepared. Three hamsters were randomly assigned to each of the seven hamster diet groups (six novaluron treatment groups and one control group).
At $1200 \mathrm{~h}$ each day for $9 \mathrm{~d}$, the hamsters were provided with $15 \mathrm{~g}$ of their respective diet. The uneaten portion of the food was collected the following day at $1200 \mathrm{~h}$, and the daily food intake and daily doses of novaluron that were ingested by the hamsters were calculated. The daily doses of novaluron for individual hamsters were compared within hamster diet groups using repeated-measures ANOVA, performed with the GLM procedure of SAS (SAS Institute 2001). The Tukey multiple comparison procedure was used to separate significantly different means. The feces voided by each hamster were collected daily for $9 \mathrm{~d}$. The feces of each hamster were placed in uncovered containers, dried at room temperature for $7 \mathrm{~d}$, and then stored at $-80^{\circ} \mathrm{C}$ until used.

Feces voided by the three hamsters in each diet group were pooled. Larval bioassays were conducted as described above using hamster feces collected after $9 \mathrm{~d}$ of feeding as larval diets. Six bioassay vials were prepared for each of the six larval diets (feces of hamsters fed a diet containing five concentrations of novaluron or a control diet). The development and mortality of sand fly larvae were monitored and statistically analyzed as described above for experiment 1 .

Experiment 3: Aging Feces Under Simulated Field Conditions. A meal-form hamster diet containing 988 $\mathrm{mg} / \mathrm{kg}$ technical novaluron and an untreated control hamster diet were prepared. Twelve hamsters were weighed and randomly assigned to each of the two hamster diet groups (total of 24 hamsters). Hamsters were fed their respective diets for $9 \mathrm{~d}$ as described above. The daily food intake and the daily doses of novaluron that were ingested by the hamsters were calculated and statistically analyzed as described above for experiment 2 .

A total of $12 \mathrm{~g}$ of feces voided by control or novaluron-treated hamsters after $9 \mathrm{~d}$ of feeding of their respective diets ( $1 \mathrm{~g}$ of feces voided by each hamster) was placed in a $120 \mathrm{ml}$ specimen cup with a 2 -cm thick basal layer of plaster of paris. The specimen cups containing feces were stored in an environmental chamber at $28^{\circ} \mathrm{C}, 90 \% \mathrm{RH}$ (conditions that simulated the temperature and humidity within a rodent burrow; Kay and Whitford 1978). The specimen cups were placed on filter papers that were kept saturated with distilled water in glass dishes. Samples of the aged feces $(2 \mathrm{~g})$ were taken from the specimen cups at $30 \mathrm{~d}$ intervals for $150 \mathrm{~d}$, and the aged feces were stored at $-80^{\circ} \mathrm{C}$ until used in sand fly larval bioassays.

Aged hamster feces were fed to second instar larvae as described above in experiment 1. Six bioassay vials were used for each of the 12 larval diet groups (feces of control or novaluron-treated hamsters aged for six time periods: $0,30,60,90,120$, or $150 \mathrm{~d}$ ). The development and mortality of sand fly larvae were monitored and statistically analyzed as described above for experiment 1 .

Experiment 4: Partial Consumption of NovaluronTreated Food by Hamsters. Meal-form hamster diets containing 0 or $988 \mathrm{mg} / \mathrm{kg}$ novaluron were prepared. Three hamsters were randomly assigned to each of the 
Table 1. Experiment 1: Mortality and longevity of second instar sand flies fed hamster feces directly treated with novaluron solutions

\begin{tabular}{ccc}
\hline $\begin{array}{c}\text { Concentration } \\
(\mathrm{mg} / \mathrm{kg}) \text { of novaluron } \\
\text { in larval diet }\end{array}$ & $\begin{array}{c}\text { Mortality } \% \\
\left(\text { means }^{a} \pm \mathrm{SE}\right)\end{array}$ & $\begin{array}{c}\text { Longevity d } \\
\left(\text { means }^{a} \pm \mathrm{SE}\right)\end{array}$ \\
\hline 0 & $0.0 \pm 0.0 \mathrm{a}$ & $\mathrm{n} / \mathrm{a}$ \\
9.88 by $10^{-5}$ & $5.0 \pm 5.8 \mathrm{a}$ & $\mathrm{n} / \mathrm{a}$ \\
9.88 by $10^{-4}$ & $2.5 \pm 5.0 \mathrm{a}$ & $\mathrm{n} / \mathrm{a}$ \\
9.88 by $10^{-3}$ & $0.0 \pm 0.0 \mathrm{a}$ & $\mathrm{n} / \mathrm{a}$ \\
9.88 by $10^{-2}$ & $0.0 \pm 0.0 \mathrm{a}$ & $\mathrm{n} / \mathrm{a}$ \\
9.88 by $10^{-1}$ & $35.0 \pm 19.1 \mathrm{~b}$ & $4.0 \pm 0.4$ \\
9.88 & $100.0 \pm 0.0 \mathrm{c}$ & $4.1 \pm 0.3$ \\
98.8 & $100.0 \pm 0.0 \mathrm{c}$ & $3.0 \pm 0.3$ \\
988 & $100.0 \pm 0.0 \mathrm{c}$ & $3.0 \pm 0.3$ \\
\hline
\end{tabular}

Values within a column followed by the same letter are not significantly different from each other, $P>0.05 ; \mathrm{n} / \mathrm{a}$, not applicable.

${ }^{a}$ Four replicates, 10 larvae per replicate.

following three groups: hamsters fed exclusively a diet containing $988 \mathrm{mg} / \mathrm{kg}$ novaluron, hamsters fed exclusively an untreated diet, or hamsters fed $1 \mathrm{~g}$ of diet containing $988 \mathrm{mg} / \mathrm{kg}$ novaluron for $3 \mathrm{~h}$ each day and then afterwards provided with untreated diet. The hamsters were fed using these protocols for $9 \mathrm{~d}$. The daily food intake and daily doses of novaluron for each hamster were calculated as described above. The feces voided by each hamster were collected daily for $9 \mathrm{~d}$ and were processed as described above.

The feces collected from hamsters after feeding for $9 \mathrm{~d}$ were pooled by treatments, crushed using a mortar and pestle, and used in sand fly larval bioassays. The larval bioassays were conducted as described above. Six bioassay vials were used for each of the three larval diet groups (feces of hamsters exclusively fed novaluron-treated or control diets, or feces of hamsters fed novaluron-treated food as a portion of their diet). The development and mortality of sand fly larvae were monitored and statistically analyzed as described above.

\section{Results}

Experiment 1: Direct Treatment of Hamster Feces. Larvae in each of the larval diet groups were observed feeding and frass was found in each bioassay vial. The percent mortality from second instar to adult was $0 \%$ for larvae fed acetone-treated hamster feces. At the concentrations of novaluron tested, the mean percent mortality of sand fly larvae fed novaluron-treated hamster feces ranged from 0 to $100 \%$ (Table 1). Mortality of larvae fed feces containing as little as $9.88 \times$ $10^{-1} \mathrm{mg} / \mathrm{kg}$ novaluron was significantly different from mortality of control larvae $(F=199.47, \mathrm{df}=8, P<$ $0.0001)$; mortality was $100 \%$ at $9.88 \mathrm{mg} / \mathrm{kg}$ and above (Table 1). The mean longevity of sand fly larvae that died after being fed novaluron-treated feces ranged from $3.0 \pm 0.2$ to $4.1 \pm 0.3 \mathrm{~d}$ (Table 1$)$.

Experiment 2: Minimum Effective Dose as a FeedThrough. The mean body weight of the 12 hamsters in this study was $143.3 \pm 3.0 \mathrm{~g}$, and the body weights of hamsters assigned to different diet groups were not
Table 2. Experiment 2: Mortality and longevity of second instar sand flies fed feces of hamsters fed diets containing novaluron

\begin{tabular}{ccc}
\hline \hline $\begin{array}{c}\text { Hamster diet novaluron } \\
\text { concn }(\mathrm{mg} / \mathrm{kg})\end{array}$ & $\begin{array}{c}\text { Mortality } \% \\
\left(\text { means }^{a} \pm \mathrm{SE}\right)\end{array}$ & $\begin{array}{c}\text { Longevity d } \\
\left(\text { means }^{a} \pm \mathrm{SE}\right)\end{array}$ \\
\hline 0 & $10.0 \pm 8.2 \mathrm{a}$ & $\mathrm{n} / \mathrm{a}$ \\
9.88 by $10^{-4}$ & $7.5 \pm 9.6 \mathrm{a}$ & $\mathrm{n} / \mathrm{a}$ \\
9.88 by $10^{-3}$ & $12.5 \pm 9.6 \mathrm{a}$ & $\mathrm{n} / \mathrm{a}$ \\
9.88 by $10^{-2}$ & $5.0 \pm 5.0 \mathrm{a}$ & $\mathrm{n} / \mathrm{a}$ \\
9.88 by $10^{-1}$ & $100.0 \pm 0.0 \mathrm{~b}$ & $5.6 \pm 0.6$ \\
9.88 & $100.0 \pm 0.0 \mathrm{~b}$ & $4.2 \pm 0.6$ \\
\hline
\end{tabular}

Values within a column followed by the same letter are not significantly different from each other, $P>0.05 ; \mathrm{n} / \mathrm{a}$, not applicable.

${ }^{a}$ Six replicates, 10 larvae per replicate.

significantly different $(F=0.24$, df $=5, P=0.9358)$. The mean daily food intake of the 12 hamsters in this study was $7.2 \pm 1.4 \mathrm{~g}$, and the amount of food eaten by hamsters in different diet groups was not significantly different $(F=0.28, \mathrm{df}=5, P=0.9256)$. The mean daily doses of novaluron for hamsters ranged from $4.8 \times$ $10^{-5}$ to $5.1 \times 10^{-1}$

Evidence of feeding was observed for larvae in each of the larval diet groups. The percent mortality from second instar to adult was $10.0 \pm 8.2 \%$ for larvae fed feces of untreated hamsters (Table 2). At the tested concentrations of novaluron fed to hamsters, the mean percent mortality of sand fly larvae fed feces of novaluron-treated hamsters ranged from 5.0 to $100.0 \%$ (Table 2). Mortality of larvae fed feces of hamsters fed a diet containing as little as $9.88 \times 10^{-1} \mathrm{mg} / \mathrm{kg}$ novaluron (daily dose $4.9 \times 10^{-2} \pm 9.7 \times 10^{-3} \mathrm{mg} / \mathrm{kg}$ novaluron) was significantly different from mortality of larvae fed feces of hamsters fed an untreated diet $(F=188.61$, df $=5, P<0.0001$; Table 2$)$. The mean longevity of sand fly larvae that died after being fed feces of novaluron-treated hamsters ranged from 4.2 to 5.6 (Table 2)

Experiment 3: Aging Feces Under Simulated Field Conditions. The mean body weight of the 36 hamsters was $150.8 \pm 10.2 \mathrm{~g}$, and the mean body weights of hamsters in the two hamster diet groups were not significantly different $(F=0.16, \mathrm{df}=1, P=0.85)$. The mean daily food intake for hamsters fed diets containing $988 \mathrm{mg} / \mathrm{kg}$ novaluron or acetone alone were not significantly different $(F=1.65, \mathrm{df}=1, P=0.19)$. The estimated mean daily dosage of novaluron was $63.1 \pm$ $10.0 \mathrm{mg} / \mathrm{kg}$ body weight.

Larvae in each of the larval diet groups were observed feeding and frass was found in each bioassay vial. The mean percent mortality for sand flies fed feces of untreated hamsters that had been aged for any of the time periods $(0-150 \mathrm{~d})$ was $<10 \%$. There were no significant differences between percent mortality at different aging periods $(F=230.34$, df $=11, P<$ 0.0001; Fig. 1).

The mean percent mortality for sand flies fed feces of novaluron-treated hamsters was significantly different from sand flies fed feces of control hamsters when the feces were aged for any of the time periods (Fig. 1). All larvae that had been fed feces of novaluron-treated hamsters aged for 0 or $30 \mathrm{~d}$ died before 


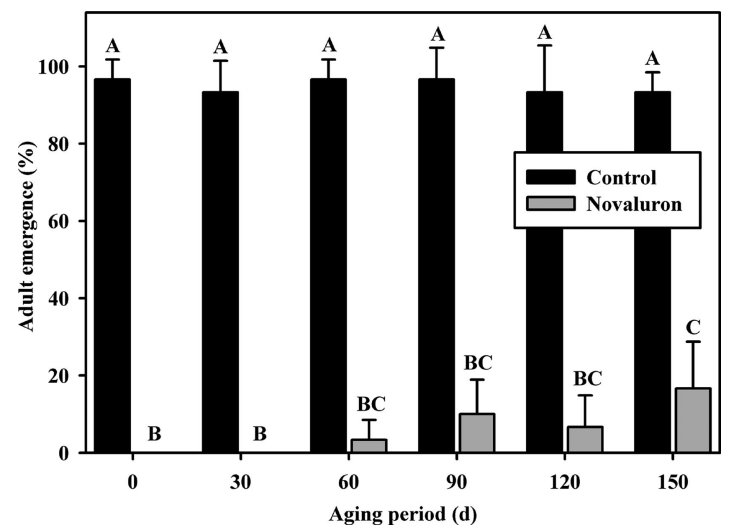

Fig. 1. In experiment 3, the percent adult emergence of sand flies fed feces of control or novaluron-treated hamsters; feces were aged under simulated field conditions $\left(28^{\circ} \mathrm{C}, 90 \%\right.$ $\mathrm{RH})$ for up to $150 \mathrm{~d}$.

adult emergence. The mean percentage of larvae that died after being fed feces of novaluron-treated hamsters that had been aged for 60 (96.7 $\pm 5.2 \%), 90$ $(90.0 \pm 8.9 \%)$, or $120 \mathrm{~d}(93.3 \pm 8.2 \%)$ was significantly higher than for larvae fed feces of control hamsters (Fig. 1). The mean percent mortality for larvae fed feces of novaluron-treated hamsters aged for $150 \mathrm{~d}$ was $83.3 \pm 12.1 \%$, which was significantly different from both larvae fed feces of control hamsters and larvae fed feces of novaluron-treated hamsters aged for 0 or $30 \mathrm{~d}$ (Fig. 1).

Experiment 4: Partial Consumption of NovaluronTreated Food by Hamsters. The mean daily food intake of the hamsters was $7.3 \pm 0.8 \mathrm{~g}$. The mean daily food intake of hamsters fed novaluron-treated food as a portion of their daily diet $(6.9 \pm 0.9 \mathrm{~g})$ was significantly different from the food intake of hamsters fed exclusively untreated $(7.4 \pm 0.8 \mathrm{~g})$ or novalurontreated $(7.6 \pm 0.7 \mathrm{~g})$ diets $(F=6.30, \mathrm{df}=2, P=$ 0.0029). The mean body weight of hamsters in this study was $136.0 \pm 13.0 \mathrm{~g}$, and the mean body weights of hamsters in the three hamster diet groups were not significantly different $(F=0.40, \mathrm{df}=2, P=0.6846)$.

Hamster diet containing $988 \mathrm{mg} / \mathrm{kg}$ novaluron constituted $14.8 \pm 1.9 \%$ of the total daily food intake of hamsters in the partial feeding group. The mean daily dose of novaluron for hamsters fed novaluron-treated food as a portion of their diet was $7.3 \pm 0.4 \mathrm{mg} / \mathrm{kg}$; the mean daily dose of novaluron for hamsters fed exclusively novaluron-treated food was $57.4 \pm 6.0 \mathrm{mg} / \mathrm{kg}$.

Larvae in each of the larval diet groups were observed feeding and frass was found in each bioassay vial. The mean percent mortality for the sand fly larvae in the untreated hamster feces larval diet group was $3.3 \pm 5.2 \%$. Sand fly larvae that were fed feces from hamsters that had consumed diets containing novaluron died before pupation (Table 3). Larvae that had been fed either feces from hamsters that exclusively had been fed a diet containing novaluron or both a diet containing $988 \mathrm{mg} / \mathrm{kg}$ novaluron and untreated hamster food were ataxic and ceased feeding, and none
Table 3. Experiment 4: Mortality and longevity of second instar sand flies fed feces of hamsters fed diets containing novaluron. Hamsters were fed novaluron-treated food as all, part, or none of their daily diet

\begin{tabular}{lcc}
\hline Hamster diet group & $\begin{array}{c}\text { Mortality \% } \\
\left(\text { means }^{a} \pm \mathrm{SE}\right)\end{array}$ & $\begin{array}{c}\text { Longevity d } \\
\left(\text { means }^{a} \pm \mathrm{SE}\right)\end{array}$ \\
\hline Control & $3.3 \pm 5.2 \mathrm{a}$ & $\mathrm{n} / \mathrm{a}$ \\
Novaluron-treated diet & $100.0 \mathrm{~b}$ & $3.6 \pm 1.2 \mathrm{a}$ \\
Partial consumption & $100.0 \mathrm{~b}$ & $3.8 \pm 1.6 \mathrm{a}$ \\
\hline
\end{tabular}

Values within a column followed by the same letter are not significantly different from each other, $P>0.05 ; \mathrm{n} / \mathrm{a}$, not applicable.

${ }^{a}$ Six replicates, 10 larvae per replicate.

pupated. The mean longevity of sand fly larvae fed feces from hamsters that exclusively had been fed a diet containing $988 \mathrm{mg} / \mathrm{kg}$ novaluron and feces from hamsters were fed both diets containing novaluron and untreated diets was not significantly different $(F=0.95, \mathrm{df}=1, P=0.3317$; Table 3$)$.

\section{Discussion}

In experiments 1 and 2, complete control of sand fly larvae was observed when the larvae were fed either hamster feces containing $9.88 \mathrm{mg} / \mathrm{kg}$ novaluron or feces of hamsters fed a diet containing $9.88 \times 10^{-1}$ $\mathrm{mg} / \mathrm{kg}$ novaluron. The concentrations that were $100 \%$ effective against sand fly larvae in experiments 1 and 2 were different by an order of magnitude, but diet and fecal concentrations of novaluron cannot be equated. Laboratory studies on the metabolism and excretion of novaluron in rats have shown that $95.4 \%$ of novaluron is eliminated in feces for up to $168 \mathrm{~h}$ (Food and Agriculture Organization of the United Nations [FAO] 2005). If hamsters excrete novaluron at a rate similar to rats, an increase in the concentration of novaluron in the feces of hamsters over the 9-d period of this study would be expected. In experiment 2 , the mean amount of food consumed by a hamster each day $(7.2 \pm 1.4 \mathrm{~g})$ was higher than the amount of feces voided by a hamster $(\approx 2 \mathrm{~g})$. Because the majority of novaluron is eliminated in feces, the concentration of novaluron in the feces of a hamster should be higher than the concentration of novaluron in a hamster's diet. The purpose of these experiments was to measure the effect of the treatments on the survival of sand flies fed feces of novaluron-treated hamsters, but the rate at which novaluron is eliminated from hamsters could be an important variable to measure in future studies.

When feces of novaluron-treated hamsters were held under simulated field conditions $\left(28^{\circ} \mathrm{C}, 90 \% \mathrm{RH}\right)$ for up to $30 \mathrm{~d}$, all larvae that consumed these feces died before pupation. A significant reduction in treated larval survival relative to control was observed when the feces were aged for up to $150 \mathrm{~d}$. Based on the findings of experiment 1 , we can conclude that feces of hamsters fed a diet containing $988 \mathrm{mg} / \mathrm{kg}$ that had been aged for $30 \mathrm{~d}$ contained at least $9.88 \mathrm{mg} / \mathrm{kg}$ novaluron (a concentration that caused complete larval mortality).

Studies on the fate of novaluron in soil have shown that between 32 and $49 \%$ of the compound can be 
present in soil after 127-195 d (FAO 2005). Therefore, baits containing $316 \mathrm{mg} / \mathrm{kg}$ novaluron (32\% of 988 $\mathrm{mg} / \mathrm{kg}$ novaluron) could be expected to be $100 \%$ effective as a rodent feed-through for larval sand fly control. However, novaluron may have been degraded at a faster rate in hamster feces than in soil because of the rapid proliferation of fungi. While we approximated the temperature and humidity of a rodent burrow in experiment 3 , in an actual field setting novaluron in feces could degrade at an even faster rate than we observed in this study. Therefore, the rate at which novaluron in feces is degraded under different simulated field conditions could be another important topic for future studies.

Novaluron-treated diet made up $\approx 15 \%$ of the food consumed daily by hamsters in experiment 4 , and the feces of these hamsters was equally as effective against sand fly larvae as feces of hamsters exclusively fed a novaluron-treated diet. The results of experiment 4 suggest that when novaluron is eliminated by orally dosed hamsters, it is uniformly distributed in the feces. This is an important observation because artificial baits for wildlife do not fully supplant naturally available food sources. The results of experiment 4 indicate that novaluron would be effective under circumstances where baits make up only a small portion of the diet of the target rodents in a field setting.

While rodents targeted in field trials of feedthrough control measures for sand fly larvae cannot be expected to exclusively consume novaluron-treated baits, a key component of potential field work would be to identify baits that are readily consumed by target rodents in different foci. The amount of food consumed by study hamsters was not affected by novaluron treatments at any of the concentrations tested in experiments 2 and 3 (significant differences were only observed in experiment 4 when hamsters were fed novaluron-treated food as a portion of their diet, which may have been a result of the frequent changing of food which disrupted the hamsters' feeding). This observation is consistent with findings of Mascari et al. (2007b), in which the authors reported that the quantity of food consumed by hamsters was not affected by concentrations of novaluron as high as $988 \mathrm{mg} / \mathrm{kg}$. It is not known whether the food intake of the different rodents that could be targeted in field trails would be similarly unaffected by novaluron treatments. However, the grain-based baits that would be prepared for field trials could contain a palatability agent, such as a vegetable oil. Palatability agents are commonly used in conjunction with rodenticides to increase bait uptake by target animals and may mask any potential odor or taste of novaluron.

The important characteristics of an insecticide used in a rodent bait for control of sand fly larvae would be (1) that it is excreted in feces of bait-fed rodents rather than metabolized, (2) that it persists in the environment, and (3) that it is effective in preventing the development and survival of sand fly larvae when the bait makes up only a portion of a target rodent's diet. In this study, significant control of sand fly larvae was observed when they were fed feces of novalurontreated hamsters that had been aged for up to $150 \mathrm{~d}$ or feces of novaluron-treated hamsters when only $15 \%$ of their daily diet was novaluron-treated food. Therefore, novaluron is a good candidate for further evaluation as a rodent feed-through insecticide against sand fly larvae. Because the results of this study suggest that novaluron could be effective as a rodent feed-through insecticide in a field setting, the next step would be to evaluate the effects of novalurontreated baits on sand fly populations in different rodent or sand fly associations.

\section{Acknowledgments}

This work was supported by a grant from the Deployed War-Fighter Protection (DWFP) Research Program, funded by the U.S. Department of Defense through the Armed Forces Pest Management Board (AFPMB). The opinions or assertions contained herein are the private views of the authors, and are not to be construed as official, or as reflecting true views of the Department of Defense. This article was published with approval of the Director of Louisiana Agricultural Experiment Station.

\section{References Cited}

[FAO] Food and Agriculture Organization of the United Nations. 2005. JMPR-Pesticide residue data. FAO, Geneva, Switzerland.

Kay, F. R., and W. G. Whitford. 1978. The burrow environment of the banner-tailed kangaroo rat, Dipodomys spectabilis, in South-Central New Mexico. Am. Midl. Nat. 99: $270-279$.

Mascari, T. M., M. A. Mitchell, E. D. Rowton, and L. D. Foil. 2007a. Laboratory evaluation of diflubenzuron as a feedthrough for the control of immature sand flies (Diptera: Psychodidae). J. Med. Entomol. 44: 171-174.

Mascari, T. M., M. A. Mitchell, E. D. Rowton, and L. D. Foil. 2007b. Evaluation of novaluron as a feed-through insecticide for control of immature sand flies (Diptera: Psychodidae). J. Med. Entomol. 44: 714-717.

Minitab Statistical Software. 2005. Minitab handbook, 5th ed. Minitab Brooks/Cole-Thomson Learning, Belmont, CA.

SAS Institute. 2001. SAS system for Windows, release 8.2. SAS Institute, Cary, NC.

[WHO] World Health Organization. 2008. Leishmaniasis. (http://www.who.int/leishmaniasis/en/).

Young, D. G., P. V. Perkins, and R. G. Endriss. 1981. A larval diet for rearing phlebotomine sand flies (Diptera: Psychodidae). J. Med. Entomol. 18: 446.

Received 6 May 2009; accepted 2 December 2009. 